\title{
Morphology and Composition of Biomineralized Ceria and Ceria-Zirconia Nanocrystals
}

\author{
$\mathrm{Li} \mathrm{Lu}^{1}$, Christopher Curran ${ }^{2}$, Christopher J. Kiely ${ }^{1,2}$, Bryan W. Berger ${ }^{2}$ and Steven McIntosh ${ }^{2}$ \\ ${ }^{1}$ Department of Materials Science and Engineering, Lehigh University, Bethlehem, PA 18015, USA. \\ ${ }^{2}$ Department of Chemical and Biomolecular Engineering, Lehigh University, Bethlehem, PA 18015, \\ USA.
}

Ceria and doped ceria nanocrystals (NCs) are of major technological importance as active catalyst support materials, particularly for environmental applications and energy conversion systems. A decrease in ceria particle size may substantially facilitate defect formation, which will increase oxygen vacancies and enhance redox activity. Zirconium is commonly doped into ceria to improve its catalytic activity and thermal stability [1-3].

Biomineralization, the formation of solid materials via enzymatic routes, is being explored as a low-cost alternative to the more aggressiveand energy intensive chemical synthesis methods typically used in oxide powder manufacturing. Silicatein, a biomolecule found in sea sponges, has been utilized in this study to synthesize ultra-small $\mathrm{CeO}_{2}$ and $\mathrm{Ce}_{\mathrm{x}} \mathrm{Zr}_{1-\mathrm{x}} \mathrm{O}_{2} \mathrm{NCs}$ in aqueous solutions at room temperature. To the best of our knowledge, we are the first group to report the successful biosynthesis of lanthanide oxide NCs. A wide variety of techniques have been applied to characterize these materials, including XRD, XPS, SEM, TEM and UV-vis spectroscopy. Here, a combination of HRTEM and STEM-XEDS data are presented to illustrate the nanostructural and compositional features of our biomineralized nano-ceria and $\mathrm{Zr}$-doped nano-ceria.

The two biomineralized samples studied exhibit narrow particle size distributions; namely $2.6 \pm 0.4 \mathrm{~nm}$ for $\mathrm{CeO}_{2}$ and $2.4 \pm 0.4 \mathrm{~nm}$ for $\mathrm{Ce}_{\mathrm{x}} \mathrm{Zr}_{1-\mathrm{x}} \mathrm{O}_{2}$, as revealed by HRTEM and STEM-HAADF imaging. They are amongst the smallest $\mathrm{CeO}_{2}$ and $\mathrm{Ce}_{\mathrm{x}} \mathrm{Zr}_{1-\mathrm{x}} \mathrm{O}_{2} \mathrm{NCs}$ ever made [4]. The ultra-small size is partly due to the low synthesis temperature, which limits the rate of particle growth after bio-nucleation. Both the un-doped and Zr-doped bio-ceria NCs are well-crystallized and adopt the cubic-fluorite structure, with the most commonly exposed surface facets being $\{111\},\{100\}$ and $\{110\}$ (Fig. 1), consistent with prior theoretical and experimental studies [5-8]. The exposure of $\{111\}$ and $\{100\}$ surface facets results in a polyhedral shape (Figs. 1(b-c)), while a pre-dominanceof $\{100\}$ facets results in cube-like morphologies (Fig. 1(a)). Most NCs in the $\mathrm{CeO}_{2}$ and $\mathrm{Ce}_{\mathrm{x}} \mathrm{Zr}_{1-\mathrm{x}} \mathrm{O}_{2}$ samples adopt a polyhedral morphology, probably resulting from the similar surface energies of $\{111\}$ and $\{100\}$ planes under ambient conditions [8-9].

STEM-XEDS analysis was carried out to assess the chemical composition of our biomineralized Zr-doped ceria NCs. Multiple individual NCs have been examined and their XEDS spectra all show the co-existence of $\mathrm{Ce}$ and $\mathrm{Zr}$. Figure 2 shows a representative spectrum obtained by subtraction of a reference spectrum (acquired from a nearby region of support) from that of the individual NC. This subtraction procedure helps to minimize the influence of trace residual precursors deposited on the carbon support film. We suspect that this is the first time individual Zr-doped ceria NCs below $5 \mathrm{~nm}$ have actually been spectroscopically shown to be $\mathrm{Ce}-\mathrm{Zr}$ mixed oxide particles. In addition, STEM-HAADF images of $\mathrm{Ce}_{\mathrm{x}} \mathrm{Zr}_{1-\mathrm{x}} \mathrm{O}_{2} \mathrm{NCs}$ show no sign of periodic Z-contrast variations, implying Ce and $\mathrm{Zr}$ cations are randomly distributed within the mixed oxide structure. Furthermore, UV-vis absorption spectroscopy reveals that the direct bandgap of our ultra-small bio-ceria and $\mathrm{Zr}$-doped 
bio-ceria are close, both at $\sim 3.6 \mathrm{eV}$, which is slightly larger than that of commercially available $\mathrm{CeO}_{2}$ powder $\left(15-30 \mathrm{~nm}, \mathrm{E}_{\mathrm{g}} \sim 3.2 \mathrm{eV}\right)$, indicating a weak quantum confinement effect [10].

References:

[1] N. D. Petkovich et al, J. Phys. Chem. C 115 (2011), p. 21022.

[2] B. M. Reddy and A. Khan, Catal. Surv. from Asia 9 (2005), p. 155.

[3] C. E. Hori et al, Appl. Catal. B 16 (1998), p. 105.

[4] O. V. Kharissova et al, RSC Adv. 3 (2013), p. 22648.

[5] R. Wang et al, RSC Adv. 3 (2013), p. 19508.

[6] A. Hartridge and A. K. Bhattacharya, J. Phys. Chem. Solids 63 (2002), p. 441.

[7] J. C. Conesa, Surf. Sci. 339 (1995), p. 337.

[8] Z. L. Wang and X. D. Feng, J. Phys. Chem. B 107 (2003), p. 13563.

[9] T. X. T. Sayle et al, Chem. Commun. 21 (2004), p. 2438.

[10] The authors acknowledge funding from National Science Foundation under the EFRI-PSBR program, grant number 1332349.

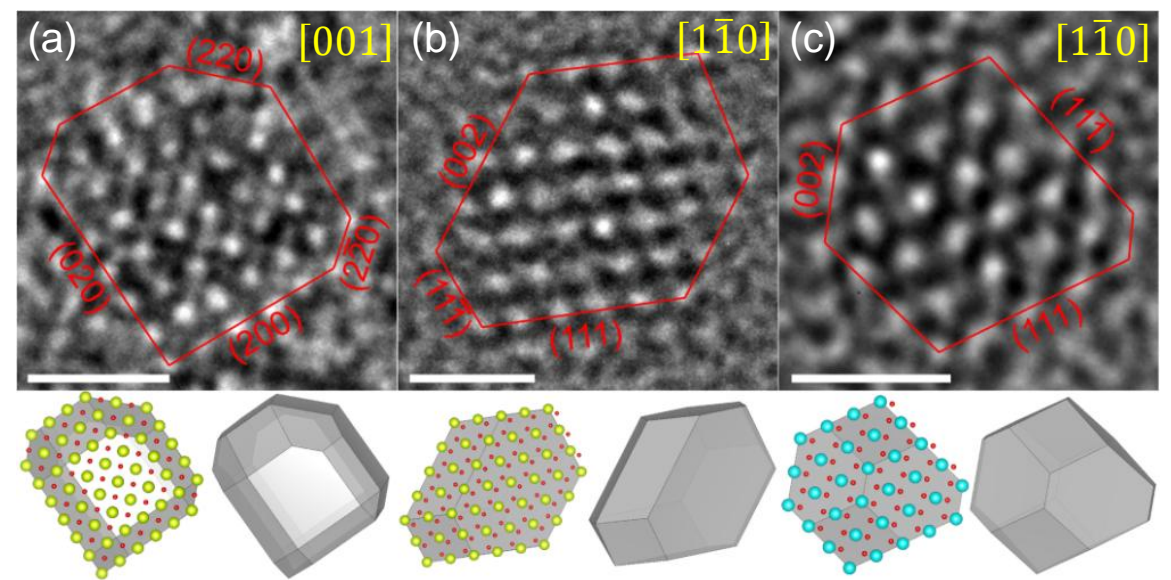

Figure 1. HRTEM images and schematic morphological representations of (a-b) bio- $\mathrm{CeO}_{2}$ and (c) bio- $\mathrm{Ce}_{\mathrm{x}} \mathrm{Zr}_{1-\mathrm{x}} \mathrm{O}_{2}$ nanocrystals. Scale bar indicates $1 \mathrm{~nm}$.

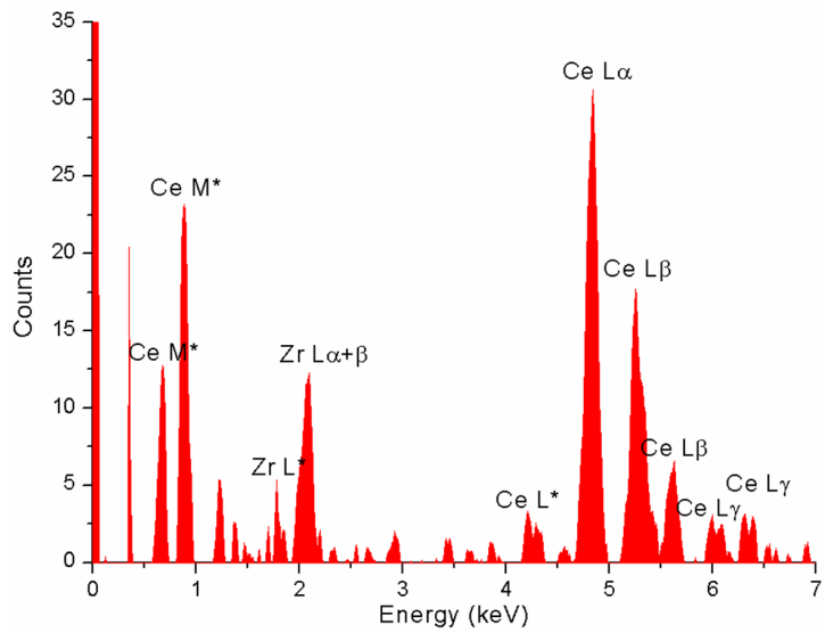

Figure 2. Representative reference-subtracted XEDS spectrum obtained from an isolated biomineralized $\mathrm{Ce}_{\mathrm{x}} \mathrm{Zr}_{1-\mathrm{x}} \mathrm{O}_{2}$ nanocrystal. 